\title{
pnmbalina
}

(8)

\section{A fada-moura: do espaço galo-romano ao espaço peninsular}

Autor(es): $\quad$ Chora, Ana Margarida

Publicado por: Associação Portuguesa de Estudos Clássicos; Centro de Estudos

URL

persistente: URI:http://hdl.handle.net/10316.2/31556

DOI: $\quad$ DOI:http://dx.doi.org/10.14195/978-989-8281-69-2_15

Accessed : $\quad$ 26-Apr-2023 12:59:58

A navegação consulta e descarregamento dos títulos inseridos nas Bibliotecas Digitais UC Digitalis, UC Pombalina e UC Impactum, pressupõem a aceitação plena e sem reservas dos Termos e Condições de Uso destas Bibliotecas Digitais, disponíveis em https://digitalis.uc.pt/pt-pt/termos.

Conforme exposto nos referidos Termos e Condições de Uso, o descarregamento de títulos de acesso restrito requer uma licença válida de autorização devendo o utilizador aceder ao(s) documento(s) a partir de um endereço de IP da instituição detentora da supramencionada licença.

Ao utilizador é apenas permitido o descarregamento para uso pessoal, pelo que o emprego do(s) título(s) descarregado(s) para outro fim, designadamente comercial, carece de autorização do respetivo autor ou editor da obra.

Na medida em que todas as obras da UC Digitalis se encontram protegidas pelo Código do Direito de Autor e Direitos Conexos e demais legislação aplicável, toda a cópia, parcial ou total, deste documento, nos casos em que é legalmente admitida, deverá conter ou fazer-se acompanhar por este aviso.

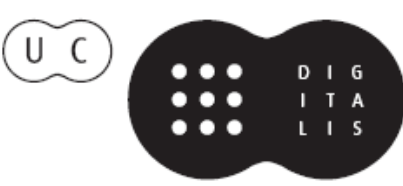




\section{Espaços e Paisagens}

Antiguidade Clássica

e Heranças Contemporâneas

Vol. III

Francisco Oliveira, Jorge Oliveira e Manuel Patrício

IMPRENSA DA UNIVERSIDADE DE COIMBRA 


\title{
A FADA-MOURA: DO ESPACCO GALO-ROMANO AO ESPAÇO PENINSULAR
}

\author{
Ana Margarida ChORA \\ Universidade Nova de Lisboa
}

\begin{abstract}
Moira-fairy is a legacy from Classical Antiquity in the Middle Ages, the same character in Gallo-Roman, Celtic and Iberian cultures, which appears associated with two types of space: the first one, a generally undefined water space of chthonic connection (lakes, fountains, rivers, wells and hollows), where the fairy changes into a serpent, such as Sybil, prophetess from classical period and fairy in French texts from XIII and XIVth centuries. This changing skill links her to another important fairy in Celtic world: Morgan le Fay.

The second space type is the result of Gallo-Roman (both Celtic and Roman) and Arab mythologies fusion in Iberian territory, which appears in Iberian-Arab imaginary under the spell of charming Moorish maidens (who offer paradise in return of freedom, as the dangerous Gallo-Roman fairies). These fairies don't come directly from Arab culture, but from GalloRoman heritage and Greek Moirae, who, as Celtic fairies, were responsible for life's destiny.

Therefore, Moira-fairy is classical feminine evidence, who rules a space dominated by different cultures.
\end{abstract}

Keywords: Celtic, fairy, Gallo-Roman, Iberian, Sybil, water.

Palavras-chave: água, Celta, fada, Galo-romano, Peninsular, Sibila.

As fadas povoam o imaginário das culturas clássica, celta, galo-romana e ibérica, surgindo, com características subtilmente distintas, quer na época a que se referem, quer no contexto folclórico em que estão inseridas. A fada da cultura clássica está mais próxima das versões míticas, assumindo contornos diferentes na passagem para a Idade Média, em que uma outra variante, a celta, hegemoniza os padrões femininos do encantamento e, em contacto com rituais autóctones do domínio romano, mistura-se com as personagens feéricas galo-romanas.

A fada é, para além do tempo, senhora do espaço. Nisto, a fada celta ultrapassa todas as outras. Numa postura de preponderância espacial, ela oferece protecção, serve de guia nos caminhos misteriosos, e deixa em aberto a possibilidade do regresso e da recompensa à mercê da decisão do herói. Ela é a fada de grande cavalgada que encarna Rhiannon dos Mabinogion (testemunho literário do folclore e mitologia celtas do País de Gales), a donzela encantadora que conduz Blandin de Cornouaille ao Outro Mundo (herói epónimo de um dos dois únicos romances arturianos provençais), e a sedutora dama do conto que Andreas Capellanus, no seu De Amore do séc. XII, apresenta como exemplo 
de amor livre e descomprometido. Nestes textos, os espaços são marcados por um percurso cavalar, herdeiro da Epona galo-romana, que legou a estas fadas a capacidade da concessão da liberdade. São personagens de mediação entre os mundos, que não se fixam em nenhum deles.

À medida que a complexificação das fadas celtas as torna mais humanas, as reminiscências da tradição oral tratam de lhes conferir raízes tanto mitológicas como folclóricas. Para além dos espaços de circulação livre, a fada apresenta características de fixação a um determinado espaço. Nesse caso, a liberdade que oferece é relativa, negociada, trocada por algo ou recusada. É aqui que surge a fada-moura. Presa a um espaço específico (que pode ser aquático, ctónico ou florestal) tem uma movimentação limitada. A fada-moura ("Moira") é uma fada de lugar, cuja designação tem origem nas Moiras da mitologia grega (Cloto, Láquesis e Átropos), divindades que teciam o destino humano, assim como Moros era o deus do destino.

A água torna-se berço e morada das "Fay", as fadas celtas de uma categoria superior.

As fadas aquáticas podem ser itinerantes (como Aglentine das Prophécies de Merlin), Morgain (fada de Montgibel em Floriant et Florete) ou Niniane (que na Suite du Merlin, na Vulgata, no Lancelot en prose, surge como Dama do Lago), ou ligadas a espaços isolados do Outro Mundo, como a Dama de Avalon (como é referido no Didot-Perceval), ou ctónicos, como Gibel de Jaufré (o outro romance provençal arturiano além de Blandin de Cornouaille). Só estas últimas, presas a um espaço, são fadas-mouras. E, embora também surjam na Matéria da Bretanha, há que ter em conta o contexto em que aparecem para as podermos identificar como tal.

Niniane é a "Dama do Lago" (lago de Diana, sua madrinha e protectora). É lá que vive num sumptuoso castelo e cria três dos principais heróis do ciclo arturiano (Lancelot, Boors e Lionel). Morgain, fada simultaneamente temida e poderosa da Matéria da Bretanha, é outra dessas figuras ligadas ao elemento aquático, cujos nomes Morg-wen (espuma do mar), Murigena ("nascida do mar", em gaélico) ou ainda Muirgen (um dos nomes da mulher aquática Liban na mitologia irlandesa) se relacionam com "Merrow", do gaélico "murúch" ou "muir-gheilt", as sereias na mitologia irlandesa e escocesa, ou ainda as "morgans", sereias da Baixa Bretanha, etimologias que parecem remeter para o imaginário não só aquático como semântico das mouras.

A água é local de encontros com fadas. No Lai de Lanval de Marie de France, o herói cavalga junto a um curso de água, onde duas donzelas o conduzem aos aposentos da sua dama, que requer o seu amor. O início do Tristan en prose, do séc. XIII, narra uma peripécia de Sador, um dos doze filhos de Bron, com uma misteriosa dama vinda das águas. Ao cavalgar junto ao mar, Sador encontra uma nave com todos os navegantes mortos, à excepção de uma bela donzela, Chelinde, filha do rei da Babilónia, prometida ao rei da Pérsia, mas que Sador faz baptizar para casar com ela. O episódio encontra alguma semelhança com De Nugis Curialium de Gautier Map (séc. XII). Aqui conta-se a história de Henno "dos dentes grandes": uma dama, noiva 
do rei de França, sobrevive a um naufrágio e conhece Henno, a quem conta a sua história, que é semelhante à de Melusina, que se transforma em dragão e desaparece pelo tecto ao contacto com água benta.

Outras fadas arturianas estão ligadas a outros elementos, como o vergel (em Yvain), as rochas (que encontramos na Suite du Merlin, e a "Roche as Saines" do Lancelot en prose, onde Gamille encanta Artur), a floresta (onde a Demoisele de Pomenglois, nas Prophecies, seduzia cavaleiros), jardins bloqueados por pedras (Madoine em Claris et Laris), e vales (como o "Val sans Retor" onde Morgain actua).

Porém, uma figura galo-romana interpõe-se na Matéria da Bretanha como fada-moura por excelência. Trata-se de Sibila. Nas Prophecies de Merlin, texto arturiano em prosa do séc. XIII, "Sebile" é uma perigosa encantadeira, amiga de Morgain e da Rainha de Norgales. As três conspiram na detenção e posse de belos cavaleiros, armam as mais ardilosas ciladas e prendem-nos no paraíso prisional dos seus domínios. Em Perceforest, longo romance que mistura a Matéria Clássica com a Matéria da Bretanha, Sebile, que detém o cargo de Dama do Lago, prende Alexandre Magno no seu castelo junto a um lago encantado, no meio da bruma, com o intuito de o curar de ferimentos de batalha, mas fá-lo perder a noção do tempo e fica grávida de um filho que será antecessor da linhagem do rei Artur.

Mas é em Le Paradis de la Reine Sibylle, texto do séc. XV, que ela reúne as componentes aquática e ctónica. Antoine de La Sale propõe-se explicar a geografia dos montes da tapeçaria da duquesa de Bourbon e Auvergne, condessa de Clermont, Fourez e Beaujou, a quem dedica a obra, referindo o lago de Sibila, junto ao qual se situava o Monte Sibilino, nos Apeninos Centrais (estando a lenda ligada a Sibila, à gruta e ao lago).

O espaço sibilino é composto de características aquáticas e ctónicas que constituem entradas para o outro mundo, designadamente uma ilha rochosa no meio do lago, lugar de cultos antigos e magia, e a vila Fougia, junto ao monte, que tinha uma fonte cuja água se dizia ser proveniente do lago e da qual nascia uma ribeira, Lasno, com águas de características maravilhosas. O monte, por seu turno, tinha um castelo, Montemoynaco, perto da caverna. A rocha que coroava o monte tinha duas passagens para a entrada da caverna. Aqui ouviase uma voz que as gentes diziam ser a voz de Sibila.

O ádito da gruta sibilina, o ambiente circundante, arredores e meios de lá chegar, bem como a própria gruta, são minuciosamente descritos. A entrada, tenebrosa e obscura, veda a realidade bela e rica do interior da gruta, onde Sibila vivia acompanhada de um séquito de gentes sofisticadas, tendo como outra característica do Outro Mundo o facto de saber falar todas as línguas. Para chegar ao domínio era preciso passar por várias portas, cada uma mais ornada do que a anterior. Ao entrarem numa pequena e rica câmara, os cavaleiros eram acolhidos, despidos das suas vestes e vestidos novamente com sumptuosidade e ostentação. Havia, no entanto, regras para permanecer naquele espaço: podia sair-se ao fim de nove dias. Mas se não o quisesse, o cavaleiro poderia permanecer até ao trigésimo dia. Depois disso, jamais 
poderia sair. O prazer daquele lugar e a companhia faziam querer prolongar a saída. O cavaleiro teria de escolher uma das damas. Ao fim de algum tempo estaria preso pelo amor. Note-se que a ausência de tempo é uma característica do Outro Mundo que se revela na fada intocada pela acção do tempo.

Ligada a um lago e a um espaço rochoso, Sibila une a mitologia ao folclore, transformando-se de noite em serpente (animal simultaneamente ctónico e aquático), juntamente com os que com ela habitavam. Ela e as suas damas separavam-se dos homens e transformavam-se em cobras e serpentes de sextafeira à meia-noite até sábado à mesma hora, voltando ainda mais belas do que antes. Note-se que é o mesmo dia da semana em que Melusina se transforma em criatura aquática.

Esta fada-moura encontra eco na figura da moura peninsular, a qual não provém necessariamente da cultura árabe invasora, mas sim do imaginário feérico espacial herdado da cultura galo-romana e celta. Segundo Consiglieri Pedroso, "as mouras encantadas eram divindades ou génios femininos das águas (...). Eram também os génios que guardavam os tesouros escondidos no centro da Terra" (Pedroso 1988 217). A moura, do latim "maura" (moura) ou do celta "mahr" (espírito), é uma variante peninsular dessa fada, sendo as narrativas sobre ela esquemas simbólicos que se repetem.

A moura-serpente, ligada a espaços aquáticos (fontes, rios e ribeiras) ou transforma-se em serpente de dia, como na lenda do Castelo de Noudar (Alentejo), ou é uma figura híbrida, metade cobra, metade mulher, como na lenda do Monte d'Assaia (Barcelos). Se a primeira encarna a divisão dual do tempo, tendo ficado presa a uma metade que impede a circularidade, a segunda simboliza a mediação com o mundo subterrâneo das riquezas em troca da submissão a provas. Esta serpente liga-se ao conhecimento e remete também para a que aparece em Le Bel Inconnu, tex to francês em verso do séc. XIII, que se transforma numa bela mulher, Blonde Esmerée, depois de revelar a identidade do herói.

Esta variante ctónica encontra paralelo num conto da Baixa Bretanha, "La Groac'h de l'Île du Lok", segundo o qual uma riquíssima e bela fada viúva que habitava uma ilha num lago prendia quem disputasse os seus tesouros. A "Groac'h" (fada) põe à disposição do jovem Houam todas as suas riquezas se este aceitar casar com ela.

As mouras são guardiãs de tesouros, que na cultura peninsular são deixados pelos mouros, mas na cultura celta são tesouros próprios com os quais as fadas seduzem os homens. A moura peninsular vive aprisionada no seu próprio encantamento, por engano ou magia, mas num profundo sofrimento.

No caso do espaço aquático, na Lenda da Moura Cássima de Loulé, de acordo com Ataíde de Oliveira, as filhas do governador maometano (Zara,Lídia e Cássima) encontravam-se encantadas numa fonte e seriam desencantadas na noite de S. João. Cássima fica eternamente presa à fonte, suspirando tristemente o seu encantamento, por ter sofrido um golpe numa perna enquanto ainda encantada sob a forma de um pão. O encantamento espacial tem, na maior parte das vezes, uma conexão ao problema do andar, que reporta ao domínio, 
deslocação, capacidade de entrada, saída e circulação no Outro Mundo. A impossibilidade de se mover pode gerar a petrificação do espaço, como a Pedra-Moura, lugar aprisionador por encantamento, relacionado com grutas, rochas flutuantes ou mouras que vivem dentro das pedras.

$\mathrm{Na}$ lenda da Moura Encantada de Vinhais (Trás-os-Montes), uma princesa moura torna-se invisível para escapar ao cerco de Almutamid, ficando presa à fraga de Pena-Cabreira. Só o seu pai podia salvá-la, mas este havia desaparecido.

As mouras devem, muitas vezes, o seu desencantamento à figura paterna, com a qual têm uma relação de cumplicidade, contrariamente à fada celta, que mantém uma relação maternal com o herói ou com o pai do herói. A fadamoura peninsular é muito mais "frágil" e vitimizada. Na cultura celta, a fada prende sem se deixar prender.

Talvez o caso mais paradigmático de sedução feminina em contexto arturiano, junto a uma rocha , seja o da "Roche aux Pucelles" da Suite du Merlin. Doze donzelas, em cima de uma rocha, indicam o caminho aos cavaleiros, mas não sem antes os fazerem permanecer no seu magnífico domínio dentro da rocha. Gauvain e Morholt aceitam guarida nos aposentos, cada um escolhe a sua donzela, mas ao fim de pouco tempo estão encantados, sem terem a noção do tempo que já passou.

A manipulação feminina é também o que acontece com Merlin, preso por Niniane numa rocha. Aí é o homem que fica preso. Num caso semelhante de sedução da mulher, que resulta no aprisionamento, presente no "Romance de Reginaldo" do Romanceiro Tradicional Português, o pajem deixa-se seduzir pela infanta. Neste romance, a voz que se ouve na Noite de S. João não é de mulher, mas sim do pobre Reginaldo encarcerado ("«Não são os anjos no céu, / Nem as sereias no mar, / (...) Prende-o tu, infanta, agora, / Pois contigo háde casar»"), que ficará preso à infanta, casando com ela (Pinto-Correia 1984 301). Aqui a voz é a dos que ficam presos por causa do desnivelamento dos mundos.

A moura é uma criatura presa na passagem dos mundos. Por que razão, então, se encontram estas figuras presas ao espaço? "Sibylle, déese des lieux", como afirmou Fernand Desonay (1930 36), vive presa à rocha, ao lago e ao encantamento, assim como as demais fadas-mouras.

Em Dona Branca ou a Conquista do Algarve, poema em dez cantos sobre o amor entre uma princesa cristã (Dona Branca, filha de D. Afonso III e freira de Lorvão) e um chefe mouro (Ibn Mahfot, conhecido entre nós por AbenAfan), assunto nacional tirado da Crónica de D. Afonso III de Duarte Nunes de Leão, explorando o folclore nacional, Almeida Garrett refere-se às "mouras encantadas" (que penteiam os cabelos nas noites de São João junto às fontes) equiparando-as aos poderes mágicos celtas, na figura do sábio e travesso Merlin. Numa nota sobre o poema, diz ainda: "É crença popular entre nós que na noute de san' João todos os incantamentos se quebram: as mouras incantadas, que ordinariamente andam em figura de cobras, tomam n'essa noute sua bella e natural presença, e vão pôr-se ao pé das fontes, ou á borda 
dos regatos a pentear os seus cabellos de ouro. Os thesouros sumidos no fundo dos poços véem á tona d'agua, e mil outras maravilhas succedem em tam milagrosa noute" (Garrett 1826239 ).

Na noite de Solstício de Verão, as fadas saem do seu domínio e circulam livremente. É também essa a ideia que transmite Shakespeare em Midsummer Night's Dream, altura do festival celta do fogo que representava o meio do Verão.

Os dias que marcam as festas solares do calendário celta caracterizam-se, devido à equidade do tempo solar com o lunar, por uma aproximação dos mundos. O mundo real e o Outro Mundo ficam ao mesmo nível, podendo circular-se livremente entre eles. É por isso que seres feéricos passam para este mundo e seres do mundo real passam para o Outro Mundo. A questão reside em poder voltar ao mundo de pertença sem se ficar preso noutra lógica temporal. Daí o perigo das mouras presas, que também podem prender...

Na cultura celta, a fada nunca está presa. É ela que prende. A "Fay" era um estatuto e não um destino. É por isso que Sibila, quando referida na Matéria da Bretanha, passa ao "cargo" de fada. A fada arturiana não oferece tesouros (mas sim poder, cavalaria e o senhorio do castelo habitado). Apenas o fazem as fadas galo-romanas e peninsulares.

A fada-moura é um ser preso num dos mundos, não conseguindo transpor a barreira do tempo, como é o caso de Sibila, contrariamente a Niniane, circulando esta livremente entre a sua floresta lacustre e a corte de Artur. E não o consegue porque não tem dupla natureza, própria dos heróis medievais, principalmente celtas. A cultura celta "inventa" a composição das personagens, mas mais a nível do herói, porque é a mulher que o compõe. As "moiras" gregas, por seu turno, estão mais próximas de uma forma mais primitiva do mito, em que ainda não são compósitas.

As mouras não são oriundas do espaço árabe-muçulmano peninsular. Simplesmente, na Península Ibérica tornam-se propriedade do fascinante, maravilhoso e mágico mundo oriental herdado da mitologia árabe. E é essa magnífica síntese que prevalece no nosso imaginário.

\section{Bibliografia}

Renée L. Curtis, ed., (1985), Le Roman de Tristan en Prose. 3 vols. Cambridge, D. S. Brewer.

M. Fernanda Frazão (1982), Lendas Portuguesas, 6 vols. Lisboa, Amigos do Livro. João Baptista da Silva Leitão de Almeida Garrett (1826), Dona Branca ou a Conquista do Algarve. Paris, J. P. Aillaud.

Walter Map, De Nugis Curialium, ed. e tr. M.R. James et al.,(1983). Oxford Clarendon Press.

F. Xavier Ataíde de Oliveira (2002), Contos Tradicionais do Algarve. Lisboa, Vega.

Consiglieri Pedroso (1988), Contribuições para uma Mitologia Popular Portuguesa 
A Fada-Moura: do espaço galo-romano ao Espaço PENinsular

e Outros Escritos Etnográficos. Lisboa, Dom Quixote.

João David Pinto-Correia, org., (1984), Romanceiro Tradicional Português. Lisboa. Editorial Comunicação.

Antoine de la Sale, Le Paradis de la Reine Sibylle, ed. Fernand Desonay (1930). Paris, Droz.

Émile Souvestre et al. (1891), Contes et Légendes de Basse-Bretagne. Nantes, Société des Bibliophiles Bretons et de l'Histoire de Bretagne. 